SAA and CRP being most induced. ${ }^{10}$ In our patient the serum concentrations of SAA and IL-6 were very high and both values decreased in a similar pattern after surgical treatment of a primary lesion. In chronic inflammatory diseases several diverse kinds of cytokines have been considered to promote the abnormal production of SAA that eventually might lead to the development of systemic reactive amyloidosis. The present study has clearly shown that in the non-inflammatory state of Castleman's disease, only IL-6 is a critical regulator for the secondary occurrence of systemic reactive amyloidosis.

We thank Dr T Nakahata, Tokyo University, for valuable suggestions. This study was supported by a grant from the Surveys and Research on Specific Diseases, the Ministry of Health and Welfare, Amyloidosis Research Committee, Japan.

1 Husby G, Marhaug G, Dowton B, Sletten K, Sipe JD Serum amyloid A (SAA): biochemistry, genetics and the pathogenesis of AA amyloidosis. Amyloid: International fournal of Experimental and Clinical Investigation 1994;1:119-37.
2 Banks RE, Forbes MA, Storr M, Higginson J, Thompson D, Raynes J, et al. The acute phase protein response in patients Raynes J, et al. The acute phase protein response in patients recieving

3 Chan WC, Hargreaves H, Keller J. Giant lymph node hyperplasia with unusual clinicopathologic features. Cancer 1984;53:2135-9.

4 Frizzera G, Peterson BA, Bayrd ED, Goldman A. A systemic lymphoproliferative disorder with morphologic features of Castleman's disease: clinical findings and clinicopathologic correlations in 15 patients. $f$ Clin Oncol 1985;3:1202-16.

5 Yoshizaki K, Matsuda T, Nishimoto N, Kuritani T, Taeho L, Aozasa K, et al. Pathologic significance of interleukin-6 (IL6/BSF-2) in Castleman's disease. Blood 1989;74:1360-7.

6 Beck JT, Hsu S-M, Wijdenes J, Bataille R, Klein B, Vesole $\mathrm{D}$, et al. Alleviation of systemic manifestations of Castleman's disease by monocional anti-interleukin- 6 antibody. N Engl F Med 1994;330:602-5.

7 Ordi J, Grau JM, Junque A, Nomdedeu B, Antonio P, Antonio C. Secondary (AA) amyloidosis associated with Castleman's disease. Report of two cases and review of the literature. Am F Clin Pathol 1993;100:394-7.

8 Perfetti V, Bellotti V, Maggi A, Arbustini E, De Benedetti F, Paulli M, et al. Reversal of nephrotic syndrome due to reactive amyloidosis (AA-type) after excision of localized tive amyloidosis (AA-type) after excision of local

9 Kazes I, Deray G. Jacobs C. Castleman disease and renal amyloidosis. Ann Intern Med 1995;122:395-6.

10 Castell JV, Gomez-Lechon MJ, David M, Hirano T, Kishimoto T, Heinrich PC. Recombinant human interleukin-6 (IL-6/BSF-2/HSF) regulates the synthesis of acute phase proteins in human hepatocytes. FEBS Lett 1988;232:347-50.

\title{
Unusual eosinophilia not detected by an automated haematological analyser in a patient with liver cirrhosis
}

\author{
O Kabutomori, Y Iwatani
}

Central Laboratory for Clinical Investigation, Osaka University Hospital, and

Department of Clinical Laboratory Science, Faculty of Medicine, Osaka University, 2-15 Yamada-oka, Suita, Osaka 565, Japan

Correspondence to:

Dr Kabutomori.

Accepted for publication 15 July 1997

Table 1 Leucocyte differential determined by three different methods in the patient with liver cirrhosis

\begin{tabular}{lllrl}
\hline & $\begin{array}{c}\text { Impedance } \\
(N E-8000)\end{array}$ & $\begin{array}{l}\text { Optical (\%) } \\
(T H M S-H 2)\end{array}$ & Manual (\%) & Reference (\%) \\
\hline Neutrophils & & & 1 & \\
$\quad$ Stab & 73.0 & 64.6 & 32 & $40-73$ \\
$\quad$ Segment & 10.4 & $9.6^{\star}$ & 11 & $18-52$ \\
Lymphocytes & 16.0 & 11.6 & 5 & $3-10$ \\
Monocytes & 0.3 & 14.1 & 50 & $0-7$ \\
Eosinophils & 0.3 & 0.1 & 1 & $0-2$ \\
Basophils & & & & \\
\hline
\end{tabular}

$\star 18.8 \%$ of this lymphocyte fraction was classified as large unstained cells.
In routine work we assess complete blood cell counts and leucocyte differentials with an automated haematological analyser using the electrical impedance method ${ }^{1}$ (NE-8000; Toa Electric Co, Kobe, Japan). In addition, we check blood films manually to determine whether there are morphological abnormalities when the data from the automatic analyser are beyond the normal ranges (white blood cells (WBC) $\geqslant 15.00 \times 10^{9} / 1$ or $\leqslant 2.00 \times 10^{9} / 1$ neutrophils $\geqslant 80 \%$ or $\leqslant 40 \%$; lymphocytes $\geqslant 60 \%$; monocytes $\geqslant 15 \%$; eosinophils $\geqslant 10 \%^{2}$; basophils $\geqslant 3 \%$; red blood cells $(\mathrm{RBC}) \geqslant 6.00 \times 10^{12} / 1$ or $\leqslant 2.00 \times 10^{12} / 1$; mean corpuscular volume $\geqslant 100 \mathrm{fl}$ or $\leqslant 70 \mathrm{fl}$; mean corpuscular haemoglobin $\geqslant 35.0 \mathrm{pg}$ or $\leqslant 25.0 \mathrm{pg}$; mean corpuscular haemoglobin concentration $\geqslant 35.0 \mathrm{~g} / \mathrm{dl}$ or $\leqslant 30.0 \mathrm{~g} / \mathrm{dl}$; platelets $\geqslant 500 \times 10^{9} / 1$ or $\left.\leqslant 50 \times 10^{9} / 1\right)$ or beyond the delta check limits (WBC, 40\%; neutrophils, $50 \%$; RBC, $20 \%$; platelets, $30 \%$ ).

\section{Case report}

We encountered a case with unusual eosinophilia according to manual detection that was not detected by the automated haematological analyser using the electrical impedance method. The patient was a 57 year old man with liver cirrhosis caused by hepatitis $C$ virus infection. Haematological data shown by the automated analyser was: WBC $3.75 \times 10^{9} / 1$; 


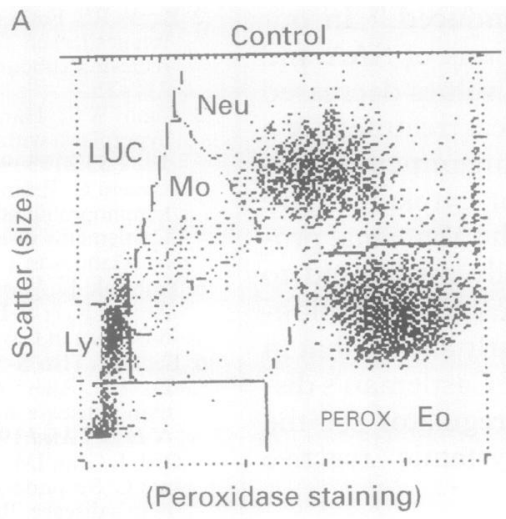

B
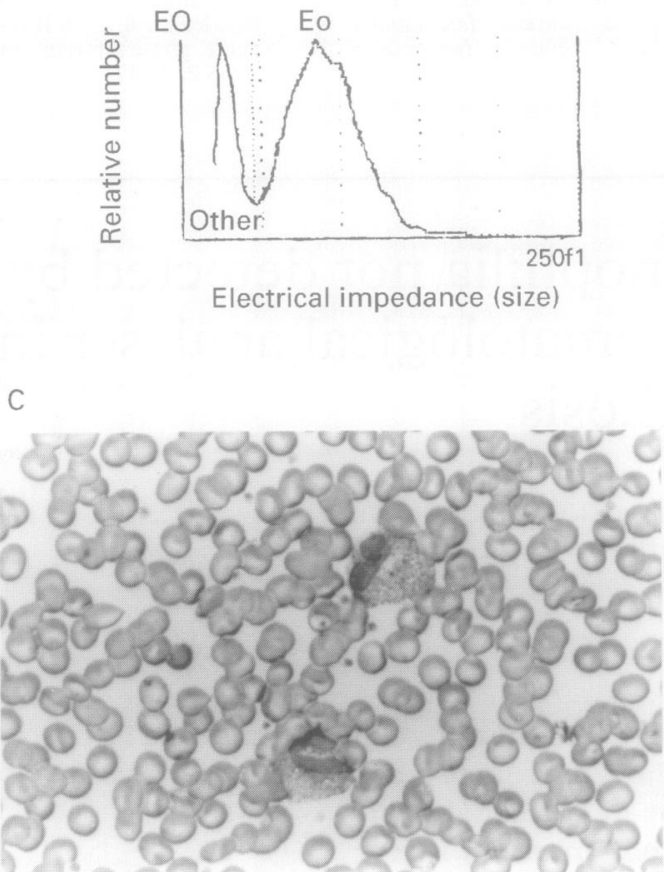
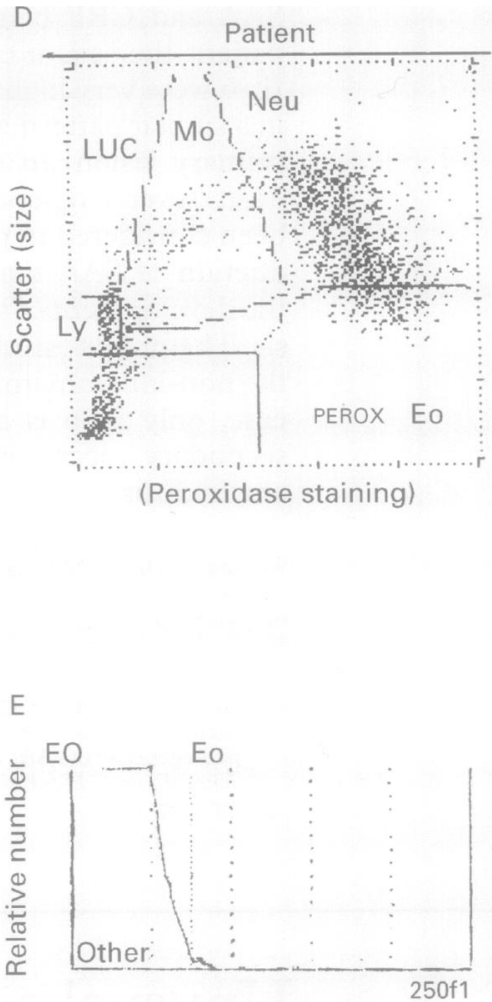

Electrical impedance (size)

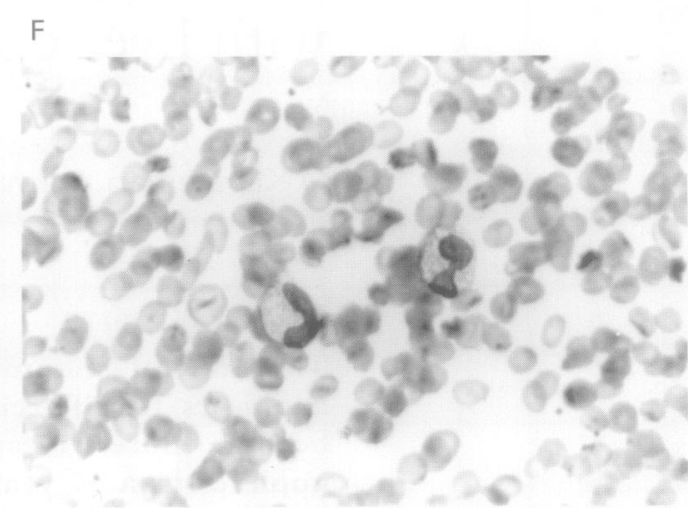

Figure 1 Leucocyte cytograms analysed with an automated optical counter (THMS-H2) (A, D) and with an automated impedance counter (NE-8000) (B,E), and peripheral blood films $(C, F)$ from a control patient with eosinophilia (left) and the patient with liver cirrhosis and unusual eosinophilia (right). Neu, neutrophil; Ly, lymphocyte; Mo, monocyte; Eo, eosinophil; LUC, large unstained cell; Other; other denucleated cell.

RBC $2.78 \times 10^{12} / 1$; haemoglobin $7.9 \mathrm{~g} / \mathrm{dl}$; haematocrit 0.242 ; platelets $58 \times 10^{9} / 1$. Leucocyte differential was abnormal but the percentage of eosinophils was normal $(0.3 \%)$ (table 1$)$. The percentage of eosinophils using the manual differential method was remarkably high (50\%) (table 1). We analysed the leucocyte differential in the same blood by another automated haematological analyser using the optical method $^{1}$ (THMS-H2; Byer Technicon, Tarrytown, New York, USA). The percentage of eosinophils was not very high (14.1\%), although it was abnormal (table 1).

Figure 1 shows the cytograms of blood from the patient and a control patient (with eosinophilic pustular folliculitis) analysed by the automated analysers using the optical and electrical impedance methods, as well as peripheral blood films. Eosinophils from the control patients were differentiated as blood cells with strong peroxidase activity and medium scatter intensity in the optical method (fig 1A), as blood cells not denucleated by alkaline treatment ${ }^{3}$ in the electrical impedance method (fig 1B), and as blood cells with polymorphonuclei and many eosinophilic granules by the manual method (fig 1C). Eosinophils in the patient with cirrhosis had a slightly higher intensity of scatter (which represents the cell size) in the optical method (fig 1D), high sensitivity against alkaline treatment for denucleation in the electrical impedance method (fig $1 E$ ), and a small number of eosinophilic granules in the cytoplasm in the manual method (fig 1F).

Although the number of eosinophil granules was lower in this patient, the activity of peroxidase was normal in each granule of eosinophils in the blood film stained by peroxidase staining. It is unknown whether the characteristics of the size and the sensitivity against alkaline treatment were related to the small 
number of eosinophilic granules in the eosinophils, but it is clear that these characteristics caused mistakes in counting the numbers of eosinophils with automated haematological analysers, especially using the electrical impedance method and alkaline treatment.

\section{Conclusion}

These data indicate that it is important during haematological examination to include a check of the blood films when cell counts measured by an automated analyser are apparently abnormal.

1 Williams WJ, Douglas AN, Michael WM. Examination of the blood. In: Williams WJ, Erslev AJ, Lichiman MA, eds. Hematology. 4th edn. New York: McGraw-Hill, 1990:9-24.

2 Wardlaw AJ, Kay AB. Eosinopenia and eosinophilia. In Williams WJ, Ernest B, eds. Hematology. 5th edn. New York: McGraw-Hill, 1995:844-51.

3 Science document. I. Basic specifications 2. Principles. Kobe: Toa medical electric corporation. 1993:2A-B.

\title{
Bronchial mucoepidermoid carcinoma after allogeneic bone marrow transplantation
}

\author{
J Sánchez, J Serrano, P Gómez, J Román, A Cosano, A Torres
}

\begin{abstract}
A 16 year old man underwent an allogeneic bone marrow transplantation (BMT) from an HLA identical sibling donor for acute lymphoblastic leukaemia in 1984. He developed chronic graft versus host disease involving the skin and kidneys. At day 400 after BMT his condition was complicated by obstructive airways disease, which was partially responsive to azathioprine and steroids. Five years after withdrawal of immunosuppressive treatment he developed dyspnoea and decreased pulmonary function test results, and steroid treatment was resumed. Fibrobronchoscopy revealed the presence of a mucoepidermoid carcinoma in the left main bronchus. After surgical laser resection, there was gradual clinical and functional improvement. There was no evidence of recurrence one year after surgery.

(f Clin Pathol 1997;50:969-970)
\end{abstract}

Keywords: bone marrow transplantation; obstructive airways disease; mucoepidermoid carcinoma

Bone marrow transplantation (BMT) has become the treatment of choice for a variety of haematological and non-haematological disorders. A wide range of pulmonary complications has been associated with the procedure; resulting from pretransplant chemoradiation, infections, and graft versus host disease (GVHD). Late (more than 100 days after BMT) pulmonary complications include: fibrosis, idiopathic interstitial pneumonia, restrictive disease, and bronchiolitis obliterans. ${ }^{2}$ Airflow obstruction after BMT has classically been associated with chronic GVHD, the use of methotrexate as prophylaxis against acute GVHD, and low serum immunoglobulin concentrations. Management of these patients includes immunosuppressive treatment although its role remains undetermined. ${ }^{3}$ The development of a second neoplasm after BMT occurs in $2 \%$ of cases but rarely involves the lung. ${ }^{45} \mathrm{~A}$ second neoplasm in the lung in a long survivor of bronchiolits obliterans after BMT has not previously been reported.

\section{Case report}

A 16 year old man presented with acute lymphoblastic leukaemia in 1984. After chemotherapy including prednisone, vincristine, anthracyclins, and methotrexate, complete remission was attained. $\mathrm{He}$ underwent allogeneic BMT from an HLA identical sibling donor. $\mathrm{He}$ had no previous history of lung disease, and pulmonary function tests and chest radiography were normal before the procedure. As a conditioning regimen he received cyclophosphamide $(120 \mathrm{mg} / \mathrm{kg})$ and total body irradiation (lung dose, 700 rads). His initial condition was complicated by grade II acute GVHD involving the skin and intestine. Seven months after BMT he developed chronic GVHD involving the skin (incontinentia pigmenti) and kidneys (nephrotic syndrome) ${ }^{6}$ which was treated with prednisone.

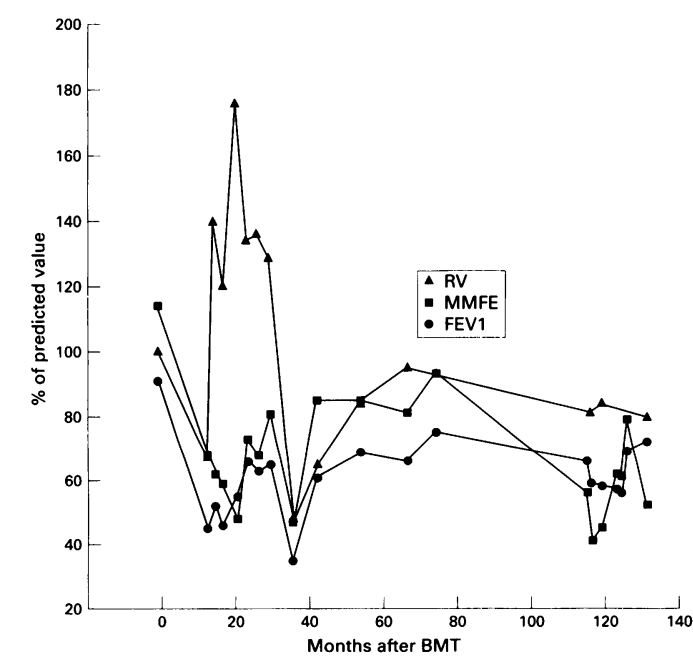

Figure 1 Long term follow up of pulmonary function tests from diagnosis of chronic airways obstruction. FEV1, forced expiratory volume in one second; $M M F E$, maximum mid-expiratory flow rate at $50 \%$ vital capacity; $R V$, residual volume. 